\title{
Analysis on Improving the Performance of International Trains Transportation on Silk Economic Zone
}

\author{
Congli Xie \\ Business School.Xi'an international university \\ Xi'an.China \\ e-mail:54471753@qq.com
}

\begin{abstract}
Keywords: China-Eu International freight trains; Silk economic zone; transprotation channel;Customs clearance mode
\end{abstract}

\begin{abstract}
Silk Economic Zone as an important channel of China going west, China-Eu International freight trains have played a very important role in promoting imports and exports, and stimulating economic zone along national economies and trade, but they have also faced to high logistics costs by a variety of constraints, the paper is based on annalysing the existing freight trains running channel and their problems, and then gives some constructive advices, finally it hopes to provide some reference for efficient operation of China-Eu International freighttrains.
\end{abstract}

\section{Introduction}

Silk economic zone, is the connectivity in the field of transportation, information, energy of Eurasian countries, to promote trade and investment facilitation, and to form a unique way of regional economic cooperation. It sets up a platform of international cooperation to promote Eurasian countries closer economic ties, more in-depth cooperation, at the same time also to make central Asia as an important strategy fulcrum and strategic channels for China going west.The core of the silk economic zone is to accelerate the economic and trade cooperation between China and the West Asia and Europe,and to open up a broader commodity market and energy resources supply[1].

The current operation of eight railway trains such as Zheng Xinou,Yu xinou not only actively promote China-eu freights, and regional economic development, but also expose some issues of affecting the transport performance such as line repetition, insufficient cargo supply etc.

\section{Current Freight trains running situation}

At present, all the trains run in a good condition, which have provided a convenient channel for enterprises to export goods to central Asia and Europe,and been satisfying with the market, and at the same time provided a foundation platform for provinces and cities to participate in the Silk road economic belt , and finally have obtained a good social effect.

Increase operation frequency and railway wagon

By the end of 2014, all over the country bound for Europe's freight trains for a total of 308 throughout the year, has sent containers 26070 TEU, exiting value of approximately $\$ 4.862$ billion. There are more than 228 columns comparing with the same period in 2013, and up 285\%, Zheng xinou accounts for a quarter of the whole reight trains, Which operates by Zhengzhou directing to Hamburg, Germany, and its density increases from the initial one month trip to twice a week, especially since November 2014, the density became two day train trip, Xi xinou also changes from the initial operational monthly class 1 to normalization operation of present monthly class 4 .The 
high frequency of the various trains has greatly facilitated the development of economic and trade exchanges between China and Euopean.

Variety of goods to meet the needs of Central Asia

Chengdu and Chongqing train cargo supply are much to laptops. The enterprise number of Zheng xinou serviced has more than 300, and they provides more than 1000 kinds of commodities, mainly including high-end shoes, clothing and other textile, industrial products and electronic products such as industrial products and electronic products,and the local supply accounted for only one third;Xi xinou cargo category covers oil drilling equipment, various types of building materials and hundreds of species of daily needs of clothing, electrical appliances, cleaning supplies, furniture and other dodge products. Much more than 206 types of goods can fully meet the needs of Central Asia.

\section{Extensive Supply distribution and obvious radiation accumulation effect}

Wuhan, Zhengzhou can take into account the central, Eastern, and even Japan, South Korea; and Xi'an can take into account the central, western, Eastern and southwestern of China, while covering Shannxi, Gansu; Ningxia, Shandong, Jiangsu, Hebei, Shanghai, Zhejiang and other places, the distribution of goods around China, the initial formation of the aggregation effect has formed.

wide radiation of destination station .

At present, the trains are basically covering the Central Asia, West Asia, Europe and other countries, to the $\mathrm{Xi}$ xinou as an example, the main purpose of the $\mathrm{Xi}$ xinou international freight trains for Ala Mutu (Kazakhstan), aktogay (Kazakhstan), Jaime (Kazakhstan), Tashkent (Uzbekistan), Bishkek (Kyrgyzstan), Astana (Kazakhstan), Dushanbe (Tajikistan), Ashkhabad (Turkmenistan),etc. according to the actual demand of goods, $\mathrm{Xi}$ xinou can also arrives at the station Qiyili, Pavlodar, Sergei Leigh and other 5 countries, 44 city and 13 cities, and basically covering the Central Asia Regional railway station and the radiation of Central Asia as a whole.

\section{Problems on international trains operating of silk economic zone}

Silk Economic zone has made a good social effect, while there are also some problems:

High route Repetition, high homogeneity service competition

In the good situation of the national advocating and actively promoting the construction of "Silk Economic Zone",Much more provinces failed to form a state-led strategy development model, all the cities were built their own railway station and bonded area, and their "trade bridgehead for European ", which due to most line repetition beside different starting and terminal points,and competition homogenization. It resulted in limited supply further dispersed, serious waste of the cause of repeated construction of funds and resources, and vicious market competition , which scatter resources and difficult to form a joint force .

\section{Shortage of return supply, low transport efficiency}

The international freight trains all over Europe are basically empty weight going back, and the return supply organization has become the biggest constraint factor for the smooth operation of the trains. The main reason is that the China-European trade structure,the current annual EU-China overland transport volume is over 7000 tons of shipping capacity over 200 million tons, but most of the goods are exported from China to Europe, while European exports to China only a small amount of goods, such as precision instruments, machinery, high-end clothing, etc. Less return goods, long-term way to bring the China- European railway transport losses across the board. To "Han xin ou" as example, in July 2010, for Foxconn Wuhan opened by the Wujiashan international railway container center to Shenzhen container classes column, however, after running a trip, the train outaged in November 2011, outages reasons largely due to the shortage of supply,which resulted in high logistics cost,and can not support the railway's normal operation.

\section{Customs clearance mode behind}

When international rail freight export clearance, business units will provides relevant documents of exports goods to the customs agents units, after the goods to the port, customs agent unit receive 
railway waybill, to the inspection and Quarantine Bureau for inspection, checking, sampling, with the inspection and quarantine Customs Clearance issued Declare at customs, customs inspection, after tax clearance, railways shipped preparation of plans. After a series of complex procedures, the time is greatly extended[2]. To Xi xin ou as an example, due to the Xi'an railway station has not yet set up a vehicle supervision and central trains,the cargo carried by Xi xin ou can not in Xi'an direct declaration, both in Alashankou border customs,which not only reduced the trains efficiency of customs clearance efficiency columns, also affected the exports of Xi'an customs area declaration.

\section{Low degree of standardization, low logistics efficiency}

Although the silk economic zone in China has basically formed the backbone of the railway, but with Central Asia, West Asia, South Asia, Europe, Africa and other foreign rail network is currently only through Horgos, Alashankou railway port , China Unicom has been less,and has not yet formed an effective exchange of domestic and foreign railway network .Moreover, parts of central and Eastern European countries the main supporting infrastructure is backward, the standard is not unified, station, storage, communication, water supply and logistics are not perfect, the proportion of railway double-track rate and electrification rate in railway operating mileage has a wide gap camparing to the world's advanced level, poor logistics channel in a certain extent hindered the China and central and East European cargo transport, storage, handling process of mechanism and automation level of ascension.

As well as by national interests, the impacts of bilateral coordination, policy convergence, different gauge, as well as inadequate port station facelift ability, poor customs inspection, slow customs clearance, long backlog and other technical factors affecting, likely to cause loss of customers and suppliers.In addition, documents, bills of different standards, the low level of information sharing data, information systems and management philosophy behind is the main reason to caused channel poor .

\section{Strategy for improving the performance of China-European international Train}

\section{Reasonable division of labor, unified coordination}

To solve the situation of trains running line repetition, vicious competition , the various provinces and cities should break barriers administrative region, relying on their own industrial advantages, foster strengths and circumvent weaknesses, complementary advantages, fully tap the existing transportation network, rational planning and layout of the logistics center, through the national coordination mechanism, develop the large-scale logistics enterprises, inter regional coordination arrangements for the distribution of goods, by taking advantage of economies of scale to achieve the sustainable development of logistics transport in different provinces and the supply situation.At the same time, the region should deepen cooperation, rational layout, make full use of local government financial subsidies, and establish a unified platform with China Railway Group as a corn,forming an unified logo, unified transport organization, unified whole price, unified service standards, unified management team, unified and coordinated platform , which will be guided by the market, local shares, shared interests, the country formed together against the other countries in channel, and avoid "fragmentation" to overseas partner countries provides an opportunity to improve charge[3]. Thus on the one hand to provide easy transport efficiency of domestic segment, but also bring some pressure on the improvement of the efficiency of the foreign transportation.

\section{Expand supply, improve transport efficiency}

- Strengthen brand building, increase the logistics strengthen brand building, increase the logistics marketing.Relying around the bonded area or container depots continue to increase publicity and promotion, to further strengthen the positioning of transport segments, and strengthen marketing capabilities;Promote China-eu trains international logistics brand construction, comprehensively improve the quality of China-Eu trains running, and form a China-Eu trains exclusive service team, optimizing service process; strengthen the research of existing supply market, development, perfect sales network, improve the incentive and 
constraints mechanism to further perfect the service.To Port District of Xi'an container center station as an example, by strengthening the marketing, Xi'an has formed in northern, southern Shaanxi, and Shanxi, Gansu, Henan, Guangdong and other provinces of the major cities as the focus, while actively visited relevant ministries and key enterprises, attracting a large number of large-scale engineering contracting enterprises entering into Central Asia to construction an engineering equipment and materials distribution in Xi'an, to effectively aggregate supply.And the coordination of large enterprises in Xi'an around the use of railway container transportation of cargo,developing policies to encourage and strengthen operational guidance,drainage on the line , cited the cargo into box, and strive to build the world's firstclass inland container transport logistics platform.Provide close cooperation platform for large shipping companies and local freight forwarding companies, effectively use of the freight forwarder's cargo capacity to increase the bulk cargo supply and wharf supply.

- Improve logistics demand by product presentation.Actively attracting leading projects, with the aid of the bonded area of product display function, through opening industrial supplies exhibition area in comprehensive bonded area (such as large equipment and high-grade imported cars, etc.), while for foreign equipment imports exhibition to promote foreign trade, attract more logistics needs.

- Actively declare import qualification.Imported cars, machinery and equipment, chemicals, agricultural products as the focus, developing the return supply to reduce total logistics costs. To "Xi xinou” for example, in return trains organization, we can fight for policies favoring on Cotton quota and import port qualification of grain, and actively promote the domestic enterprises to import cotton, meat products from Central Asia, through the expansion of agricultural and sideline products import, For Abundant supply,and promoting the operation of the return trains[4].

- Actively declare cross-border e-commerce import and export qualification.

- We should actively declare cross-border e-commerce import and export qualification, to further expand the scope of import and export business, improve the transaction volume, so as to ease the unfavorable supply shortage situation of the trains.

\section{Open up the green channel clearance, simplifying customs procedures}

For complicated customs clearance procedures, government and relevant transport authorities should be more communication and negotiation with other countries, and actively build high-quality service platform. In this regard, cities should promote to simplify the process of customs clearance procedures for international transport as soon as possible, for example, take one vote clearance, territoriality declaration, port clearance and other clearance mode.along with Customs in close contact, monitoring shipment,arrival,departure of the goods, realizing the information exchange, resolving possible problems in advance to realize the goal- one declaration, one inspection and one release," to ensure the smooth clearance of goods.

\section{Other suggestions}

- Strengthen the government, civil double cooperation. Establish an inter-governmental international cooperation system and dispute settlement mechanism, not only play the role of the relevant international nongovernmental organizations, to foster close cooperation with the regional economy along the international transport, regional customs clearance, inspection and quarantine, and customs clearance procedures and other aspects of optimization, but also establish and improve a dispute settlement mechanism of international Rail transport in logistics, trade and other areas, to eliminate trade barriers, reduce conflict and achieve channel transport facilitation in a fair and impartial judicial environment [5].

- Develop a comprehensive transportation system. Do seamless link between railway and aviation, water and other modes of transport to ensure the high-speed operation of the silk economic zone. 


\section{References}

[1] Gao Xincai.Development of Silk Road economic belt and channel Economic, Chinese Circulation Economy, vol 4. April.2014.pp.23-26

[2] Luo Gang.Research on the coordination and promotion of the transportation system in the Silk Road Economic Zone. Research and development.vol 2.Feb.2014.51-53

[3] Wang Zhengming.Research on the development strategy of the Silk Road Economic Zone.Journal of Railway Engineering.vol 1.Jan.2014.25-27.

[4] Zhang Jianwei.Research on the operation management and development of the new Eurasian Continental Bridge.Railway transportation and economy.vol 6.2014.29-32

[5] Yangliqiong, Enjoy the achievement of "Yu Xinou, create the Silk Road Economic prosperity[J], Continental Bridge, vol 7.July.2014.pp:33-36 